\title{
PERSPECTIVA HISTÓRICA DE LA LIBERTAD CREATIVA Y EL RECONOCIMIENTO ARTÍSTICO EN LA INDUSTRIA DEL COMIC BOOK ESTADOUNIDENSE (1935-1986)
}

\section{AMERICAN COMIC BOOKS BUSINESS' CREATIVITY FREEDOM AND ARTISTIC RECOGNITION IN HISTORICAL PERSPECTIVE (1935-1986)}

Rodríguez Moreno, José Joaquín (University of Washington/Universidad de Cádiz) *

\section{RESUMEN}

Las industrias culturales son negocios no convencionales que necesitan ofrecer incentivos particulares a sus empleados, entre ellos libertad creativa y reconocimiento artístico. Pese a ello, la industria del comic book se apoyó en un rígido sistema de producción que, durante sus primeras décadas de vida, daba poco o ningún reconocimiento a la mayoría de sus trabajadores. El presente artículo se adentra en las razones por las que ese primer sistema de trabajo comenzó a cambiar y el contexto que ayudó a dicha transformación. Para ello, analizamos el sistema de producción, las ventas y las propias impresiones del personal creativo.

Palabras claves: Sistemas de producción, historia de la historieta, estudios culturales, libertad creativa, cultura de masas. JEL: L23.

\begin{abstract}
Cultural industries are nonconventional business which need to offer special incentives to their workers - creative freedom and recognition among them. Nonetheless, in its first decades of life the comic book industry used a rigid system of production and didn't give any recognition to most of its employees; it needed nearly thirty years to start to change to another production system. This text wants to know why that first system started to change, and what circumstances helped this change. In order to do it, we analyze the production system, the sales and the perspective of the creative staff.
\end{abstract}

Key words: Production systems, comic history, cultural studies, creativity freedom, mass culture. JEL: L23.

\section{INTRODUCCIÓN}

Las industrias culturales, y sobre todo aquellas dedicadas a la creación de obras de ficción como es el caso de las editoriales de comic books, poseen una serie de características particulares que las diferencian de otros tipos de sectores empresariales. De este modo, sería impensable que el trabajador que participa en la fabricación de un automóvil exigiera al empresario que le permitiera montar el vehículo a su manera, que se incluyera su nombre en el producto final o que le bonificase por cada unidad vendida que él personalmente hubiese montado. Sin embargo, en industrias como la de comic book estadounidense sí que resulta a día de hoy una práctica habitual que se ofrezca un margen de libertad creativa a las personas

* Northwest-Cadiz Program, University of Washington/Universidad de Cádiz, tebeoteca@uca.es Recibido: Enero de 2017. Aceptado: Mayo de 2017. 
que escriben y dibujan las historietas, además de dárseles crédito por su trabajo y ofrecérseles una gratificación económica por las ventas, incluso si no son ellos los que crearon los personajes que aparecen en las historietas que crean. Estas diferencias entre un sector y otro se deben, obviamente, a que un trabajo creativo no es igual a uno mecánico.

No obstante, esto no siempre ha sido así en la industria del cómic. Durante más de cuatro décadas, lo habitual fue que los autores cobrasen igual que el trabajador de una cadena de montaje, que se les pidiera que se adaptasen a la línea estilística de la editorial y que se potenciara una forma de trabajo disciplinado que dejaba un espacio muy limitado a la creatividad. Al mismo tiempo, los comic books presentaban a unas pocas "estrellas" tras las que se hallaban docenas de trabajadores anónimos que no recibían más reconocimiento que un pago por página producida. Sin embargo, aunque el estudio de la industria del comic book cada vez es más común tanto en Estados Unidos como en España, el estudio de la libertad creativa y el reconocimiento artístico se ha tratado de forma bastante limitada. Esto es en parte culpa del tipo de estudios que se han realizado, donde principalmente han primado dos perspectivas: la de las editoriales y la de autores concretos (las "estrellas" a las que nos referíamos). De este modo, el estudio de las editoriales ha dado como resultado textos teóricos que mencionaban las transformaciones en el sistema de producción y acreditación, pero silenciaban los conflictos existentes al estudiar la creación de los cómics desde la perspectiva de las editoriales; un ejemplo de ello lo tenemos en las obras de Les Daniels dedicadas a las editoriales Marvel (1991) y DC (2003). Por otra parte, las biografías de autores concretos se centran en su lucha por obtener un mayor reconocimiento, un mejor salario o el derecho a explotar sus propias creaciones, pero estos conflictos no se presentaban como un problema generalizado entre las empresas y sus empleados, sino como choques particulares entre los editores y un autor concreto, tal y como se ve en la obra de Mark Evanier dedicada a Jack Kirby (2007).

El presente artículo busca romper con esta tendencia y mostrar cómo evolucionó de forma global el concepto de libertad creativa y reconocimiento artístico (dentro del cual destacamos no solamente el ser acreditado como autor de conceptos o historias, sino también el recibir algún tipo de compensación por la explotación comercial de la misma) en la industria del comic book desde los orígenes de esta en los años treinta hasta mediados de los años ochenta, cuando la industria adoptó los elementos que hoy son característicos de ella. A lo largo de dicha trayectoria buscamos responder a la pregunta: ¿qué es lo que ha llevado a una valoración mayor de los autores, su creatividad y su trabajo? Y al mismo tiempo buscamos conocer qué elemento ha sido el que más ha primado entre los autores, la libertad de crear las obras a su manera o el reconocimiento de su trabajo, contextualizadas en el momento en que se produjeron para entender su preponderancia.

\section{METODOLOGÍA}

La falta de trabajos sobre la libertad creativa y el reconocimiento artístico en el mundo del cómic nos obliga a trazar nuestro propio camino a la hora de abordar este tema, pues no existe un método al respecto, ni cuantitativo ni cualitativo. Es por ello que hemos decidido emplear las fuentes habituales a la hora de estudiar el cómic, a saber, las cifras de ventas, el número de series producidas y las declaraciones de los autores, apoyando todo esto en los trabajos teóricos sobre el mundo del cómic que ya existían.

De este modo buscamos conocer, en primer lugar, las condiciones de trabajo y la remuneración existente en la industria, para lo cual son imprescindibles las palabras de los guionistas y dibujantes, que incluso cuando no hablan desde una perspectiva global nos 
permiten reunir información que, al cotejarla con las palabras de otros autores y la literatura especializada, hace posible medir los intereses y preocupaciones del personal creativo de las editoriales. Obviamente no es posible contar con la opinión de todos los autores que han trabajado en la industria del cómic, por lo que hemos procurado reunir las declaraciones de más de una treintena de autores lo más variados posibles, tanto por su repercusión en la industria como por la época en la que trabajaron y el papel que desempeñaron en las editoriales.

Por otro lado, las ventas y el número de series producidas nos permiten conocer cómo funcionaba el negocio de los cómics, lo cual resulta imprescindible para entender tanto los momentos de tensión como aquellos otros en los que los autores se plegaron a la voluntad de las editoriales. $\mathrm{Y}$ es que es imprescindible conocer las necesidades de las empresas, sus fuentes de ingresos y el éxito de sus productos si queremos comprender el papel que jugaban los autores.

De este modo, entendiendo tanto el contexto de la industria como la percepción de los autores, esperamos dar un primer paso en la comprensión de estos aspectos que resultan clave para una industria cultural como es la del cómic estadounidense.

\section{EL MODELO DE PRODUCCIÓN CLÁSICO (1935-1960)}

La aparición de la industria estadounidense del comic book a principios de los años treinta del pasado siglo no fue realmente un proyecto empresarial claramente definido, sino más bien un proceso de prueba y error por parte de varios emprendedores con recursos económicos limitados, como se deduce de las medidas adoptadas por los primeros editores de aquella década, que reaccionaron improvisando sobre la marcha a los problemas y oportunidades que se les iban presentando. De este modo, Maxwell C. Gaines, el comercial de una imprenta neoyorquina, tuvo en 1933 la idea de reeditar en formato revista los cómics que desde hacía ya tres décadas se venían publicando en la prensa (Barrier, 1982). Posteriormente, en 1935, el escritor y antiguo oficial Malcom Wheeler-Nicholson concibió un método para abaratar costes: en lugar de pagar por reeditar material publicado en los periódicos, contrató a jóvenes e inexpertos dibujantes para que creasen sus propias historietas (Daniels, 2003). En 1936, cuando el mercado comenzaba a atraer a un público cada vez más numeroso, la iniciativa emprendedora de los dibujantes en paro Jerry Iger y Will Eisner de crear un taller que produjera material por encargo para las editoriales hizo más fácil la inversión en la industria del cómic, ya que libraba a los inversores de la búsqueda de talentos y las decisiones creativas (Eisner, 1997).

Es indudable que la Gran Depresión jugó un papel importante a la hora de proveer de jóvenes autores a la naciente industria del comic book. Con una crisis industrial que desde 1929 había reducido a la mitad la producción de las fábricas y había disparado las cifras de desempleados de los dos hasta los quince millones (Zinn, 1999), a los primeros editores no les resultó difícil encontrar a jóvenes receptivos a la idea de ganar dinero dibujando, si bien la debilidad económica de las nuevas empresas se mezcló con la ingenuidad de los primeros dibujantes que llegaron al negocio, como recuerda el artista Sheldon Mayer:

Mi primer trabajo en los cómics fue para Wheeler-Nicholson [de DC Comics]. Acudí a su oficina para mostrarle mi portafolio y me contrató al momento. Estaba asombrado con mi trabajo y yo no sabía que la enorme cantidad de dinero que me había prometido era pura palabrería (...). En los meses siguientes envié cuarenta o cincuenta páginas escritas y dibujadas para media docena de números de New Comics y New Fun. Trabajaba de día en una fábrica y producía el 
material para Nicholson por la noche (...). Nicholson nunca llegó a pagarme el dinero que me debía (1975).

A pesar del riesgo que existía de no cobrar, muchos jóvenes dibujantes probaban suerte porque necesitaban dinero para ayudar a sus familias, como le sucedía al dibujante Jack Kirby, que mantenía gracias a su habilidad con el lápiz tanto a sus padres como a su hermano pequeño (Kirby, 2005). En algunos talleres se aprovecharon de esta necesidad para obtener el máximo beneficio, como narra el dibujante Irwin Hasen:

Era la Gran Depresión. Tenías que ganarte la vida, ganar pasta. Aprendimos a hacer cómics de forma autodidacta (...). Trabajábamos como colegiales en un escritorio, y él [el director del taller] se sentaba frente a las mesas. Nos llamaba igual que un profesor llamaría a un alumno, y nos preguntaba: «¿Cuánto necesitas para vivir?». Esa era la maravillosa manera de calcular nuestro sueldo. Era un sistema totalmente asqueroso (1999).

Puesto que los comic books obtuvieron rápidamente un público fiel que no paraba de crecer, las editoriales y los talleres pedían a los autores que dibujasen el mayor número de páginas posibles. Mayer, que tras su nefasta experiencia con Wheeler-Nicholson había obtenido un puesto como editor de la editorial All-American Publications, explicaba con las siguientes palabras la filosofía de trabajo que tanto él como otros muchos editores y directores de taller aplicaron en esos años: “¡Produce rápido! Todos nuestros chicos tenían que aprender a hacerlo” (1975). Pero no hacía falta que los editores insistieran demasiado en esta idea, puesto que los sueldos bajos y la costumbre cada vez más extendida de cobrar por página realizada hacía que los autores fuesen los primeros interesados en aumentar la producción, conduciendo a frenéticas jornadas de trabajo como esta que describe el dibujante Jules Feiffer:

El negocio estaba en expansión. Cada día aparecían nuevos títulos, muchos de ellos dibujados durante un fin de semana (...). Los dibujantes permanecían sentados en habitaciones abarrotadas, produciendo cuanto podían, ya que cobraban una tarifa por página entregada. Por dibujar una página a lápiz, aplicar luego las tintas al dibujo y finalmente colocar los textos en los bocadillos se pagaban diez dólares, a veces menos (...). No había ni un momento de descanso. Algunos trabajaban en una oficina durante el día y por cuenta propia de noche: es difícil salir del trabajo a las 17:30, irse a casa y dibujar hasta las 4:00, levantarse a las 8:00 y acudir a la oficina. Y los fines de semana eran aún peores. Un amigo podía llamarte pidiéndote ayuda: le habían contratado para hacer un cómic de sesenta y cuatro páginas -un nuevo título con nuevas series, nuevos héroes- que había que idear, escribir, dibujar (...). Dieciocho horas de trabajo al día. Bocadillos para desayunar, almorzar y cenar. En ocasiones una cerveza, pero no con frecuencia. Y nada más fuerte. Nadie se atrevía a bajar el ritmo (2003).

Pese al esfuerzo de los autores, la demanda de nuevos historietas y títulos seguía creciendo. Para entender este aumento, basta con ver el incremento de títulos de dos de las editoriales más importantes de la época, Timely Comics y DC Comics, que si en 1940 publicaban en total veinticinco y ochenta y ocho números de sus series, respectivamente, tan solo un lustro después ya alcanzaban los 122 y 135 (Rodríguez, 2014). Esta necesidad de aumentar la producción, sumado al deseo de los autores de ganar más dinero, llevó a desarrollar nuevas formas de división del trabajo, tendiéndose a una especialización, de tal manera que las plantillas de las editoriales y los talleres se especializaban en una única función, trabajando de esa forma más rápida y eficientemente. En el taller de Will Eisner se aplicaba la siguiente forma de trabajo: "Hacíamos cómics igual que Ford hacía coches. Yo 
escribía la historia y diseñaba a los personajes, otra persona dibujaba la historia, otra lo entintaba y otra la rotulaba" (Wright, 2003). De hecho, como si de una fábrica realmente se tratase, los trabajadores de las editoriales se organizaban en diferentes salas según la función que desempeñaran (Renée, 2006). De este modo, en Timely Comics, había una oficina para editores y otra para sus ayudantes, una sala de dibujantes y otra de escritores, además de una última estancia donde trabajaban quienes entintaban los dibujos a lápiz (Lee, 1947). Pero a medida que cada trabajador se especializaba en una parte del sistema productivo, también iba perdiendo conexión con el resto del proceso creativo; así describía el dibujante C.C. Beck la división de tareas que se daba en la editorial Fawcett:

Los guiones eran preparados por el departamento editorial, los dibujos por el departamento artístico. Los escritores, que trabajaban bajo la supervisión de un editor, no tenían voz ni voto en lo tocante a los dibujos; los artistas, que trabajábamos bajo la supervisión de un director artístico, no teníamos nada que decir sobre las historias que nos entregaban para dibujar (2010).

Como ya no había una sola persona encargándose de un personaje o una serie, sino un equipo amplio, los editores apostaron por una producción homogénea, de tal forma que cada serie poseyera un estilo característico al que tanto guionistas como dibujantes debían amoldarse, tal y como explicaba el dibujante Sheldon Moldoff: "En aquellos días, la forma en que trabajábamos era muy diferente de la que se trabaja hoy día: «Queremos que hagas algunas historietas de Captain Midnight. Te daremos algunos números antiguos y simplemente mantén ese estilo»” (2011). También era habitual la imitación de estilos narrativos por parte de las editoriales más pequeñas, que buscaban así emular el éxito de las más grandes y con mayor éxito, marcando a su personal creativo un camino muy concreto que muchas veces no dejaba lugar al desarrollo artístico ni permitía el rendimiento óptimo de sus mejores autores, como el guionista de Nedor Comics Norman Fruman reconocía: "En aquella época nuestra principal rival era EC Comics, y [nuestro jefe] simplemente asumía que podíamos duplicar lo que el personal creativo de EC hacía. [Algunos dibujantes] siempre eran presionados para hacer cosas que se escapaban a sus, por otro lado, grandes talentos” (Vance, 2006).

A pesar de que este modelo de producción que hemos estado viendo limitó la creatividad, lo cierto es la industria del cómic no paró de crecer desde mediados de los años treinta hasta principios de los cincuenta. De este modo, Action Comics (el título en el que aparecían las aventuras de Superman) de DC Comics pasó de vender doscientos mil ejemplares en junio de 1938 al medio millón a finales de aquel año, y aún habría de mejorar las ventas en los meses siguientes (Wright, 2003). Esto no fue algo excepcional, ya que durante los años de la Segunda Guerra Mundial, pese a las restricciones de papel impuestas por el racionamiento, la editorial Timely lanzaba tiradas de entre 250.000 y 500.000 ejemplares, vendiendo un 90\% de las copias que ponía en circulación (Fago, 2001). Una vez acabadas las restricciones de la guerra, las editoriales aumentaron sus tiradas y lanzaron aún más títulos, de tal modo que si en 1942 había 143 series mensuales (Raphael y Spurgeon, 2003), en 1948 ya se publicaban 297 (Zorbaugh y Gilman, 1949).

Esta mejora de las ventas permitió que las editoriales crecieran, la estabilidad económica del personal creativo aumentara y los sueldos experimentaran una mejora. De este modo, frente a los diez dólares que Feiffer decía que un autor podía cobrar a finales de los años treinta por hacer una página escrita, ilustrada, entintada y con los textos ya colocados en los bocadillos, durante la Segunda Guerra Mundial solamente una página de guión podía pagarse a siete dólares, cobrándose quince por el dibujo a lápiz, diez por las tintas y dos por el 
rotulado de los bocadillos (Feiffer, 2003). Además, era común que a medida que un dibujante mostrase su valía se le fuera aumentando la tarifa por página que cobraba, de tal modo que cuando el dibujante Allen Bellman comenzó a trabajar sin prácticamente ninguna experiencia en la industria del cómic solamente cobraba unos veinticinco dólares semanales, si bien dicha cifra aumentó a los cuarenta y cinco dólares tan solo unos meses después (Bellman, 2005). De hecho, excepcionalmente hubo dibujantes especialmente populares como Joe Simon y Jack Kirby que no solo mejoraron sus sueldos, sino que incluso llegaron a cobrar un porcentaje sobre las ventas (Simon, 2008).

Pese a estas mejoras en la situación económica del personal creativo, las editoriales fueron inflexibles con todo lo relativo a los derechos de autoría: todo cuanto creaban sus empleados (desde la página dibujada hasta los personajes y conceptos) pertenecía a la empresa. De este modo, los creadores de Superman, Jerry Siegel y Joe Shuster, habían vendido en 1938 la primera historieta de Superman junto con los derechos sobre el personaje por 130 dólares (Daniels, 1998). El editor y autor Joe Simon reflexionaba años después, no obstante, explicando que en aquella época habría sido imposible que los autores hubiesen actuado de otra manera:

Antes de ridiculizar a Siegel y Shuster, tenéis que entender cómo eran aquellos tiempos y aquella industria. Todos éramos bastante jóvenes (...). Joe y Jerry eran adolescentes. Simplemente éramos felices de ver nuestro trabajo publicado. Todos y cada uno de nosotros firmábamos sin pensarlo cualquier papel con tal de poder seguir trabajando (...). ¿Cuál era la alternativa? (...). Era la Gran Depresión, ya sabéis, y no era fácil encontrar trabajo. Así que firmábamos lo que fuera por cobrar el cheque... (Simon y Simon, 2003).

Esta idea también la vemos en el editor y dibujante Joe Kubert, que al recordar aquellos años no dudaba en mencionar las penurias de la época como un factor clave a la hora de considerar la relación del autor con la editorial:

Ni siquiera se nos pasaba por la cabeza obtener los derechos o la propiedad de lo que hacíamos; nos sobraba con que alguien comprase nuestro trabajo. Cuando compraban mi material, sentía que lo compraban todo (...), simplemente intentábamos encontrar algo seguro a lo que aferrarnos (Kubert, 2005).

Otro factor a tener en cuenta son los pobres resultados que lograron los pocos autores que decidieron luchar en los tribunales por recuperar los derechos de sus personajes. El caso más famoso fue justamente el de Joe Shuster y Jerry Siegel, que llevaron a DC Comics a los tribunales en abril de 1947 con la esperanza de obtener cinco millones de dólares y recuperar los derechos de Superman, si bien el juez decidió que la venta del personaje había sido legal, compensándoles con una cantidad mucho menor de la que esperaban, tan solo cien mil dólares. Como resultado, DC no volvió a contar con los servicios de ambos autores e, incluso, dejó de acreditarles como los creadores del personaje (Daniels, 1998). Era, a todas luces, una victoria pírrica que dañó más las finanzas de los autores que las de la editorial.

Pero esto no quiere decir que los creadores de un personaje de éxito fuesen marginados por la editorial, antes al contrario, el fortalecimiento de la industria permitía que esta les ofreciera un trato económico ventajoso mucho mejor que el del resto del personal creativo. Por ejemplo, Lew Sayre Schwartz, que fue ayudante del cocreador de Batman, Bob Kane, recalcaba en los siguientes términos el éxito de su jefe: "Se convirtió en una celebridad de la noche a la mañana con Batman. Cuando lo conocí en Florida en 1946 ya ganaba 50.000 dólares al año, y eso en 1946 era mucho” (Daniels, 1998). Además, crear un concepto o un personaje popular permitía a un autor conservar su propio estilo y recibir cierto 
reconocimiento por parte de la editorial, como señalaba C.C. Beck, cocreador del popular superhéroe Captain Marvel: "Me dieron el cargo de artista jefe y me pusieron al frente de una oficina llena de ayudantes, otorgándome de ese modo cierto reconocimiento; sin embargo, [los demás] nunca recibieron ningún crédito” (Beck, 2010). De hecho, incluso si un autor no conseguía crear un personaje especialmente popular, la mejora de las tarifas por página hizo que el sueldo que se cobraba durante los años cuarenta y primeros cincuenta permitiese una vida digna, sobre todo si se era un autor rápido, pues la oferta de trabajo era enorme. Un ejemplo de esto lo tenemos en el dibujante Don Heck, que en 1949 empezó a buscar trabajo en la industria del cómic: "Decidí llamar el mismo día a tres editoriales diferentes. Decidí probar suerte a ver si les interesaban mis servicios. Era cuestión de coger el teléfono y ver si tenía suerte. Y de ese modo obtuve dos trabajos en un mismo día. Ni siquiera hice la tercera llamada” (Heck, 2011).

Es por ello que los autores de los cómics, incluso cuando no se encontraban satisfechos a un nivel artístico con lo que estaban haciendo, se hallaban a gusto dentro una industria que les había ayudado a capear la Gran Depresión y que les había ofrecido, posteriormente, una estabilidad económica; en palabras de Jack Kirby: "Mi objetivo era el mismo que el que se había marcado mi padre: ganarme la vida y tener una familia. Estaba en el buen camino. Mi sueño era tener dinero para mantener a mi familia y poder vivir en una casa que me gustase" (Kirby, 1990).

\section{LA REVOLUCIÓN MARVEL (1961-1978)}

El proceso de producción de los cómics se mantuvo invariable durante los años cincuenta, y eso a pesar de que diversos factores se coaligaron para dañar a la industria: de un lado, la televisión robó una parte importante del público a los cómics y provocó una caída de ventas significativa (Savage, 1990), mientras que las campañas públicas contra el contenido de los cómics y la quiebra de la principal distribuidora ayudaron a dar el golpe de gracia a muchas editoriales (Raphael y Spurgeon, 2003). La caída de ventas se puede percibir fácilmente incluso en la principal editorial de la época, Dell Comics, que pasó de vender un total de 2.850.000 ejemplares de su título más popular en 1952 a 1.004 .901 en 1960 (Carlson, 2005). De igual modo, la desaparición de editoriales también se constata fácilmente si miramos el número de series en el mercado, pues frente a los aproximadamente 650 títulos que se publicaron entre 1953-1954, dos años después la cifra era solamente de 250 (Savage, 1990).

No obstante, pese a que en los años cincuenta no hubo cambios en la forma de producir las historietas, esta primera crisis de la industria sí que tuvo dos importantes consecuencias. La primera de ellas fue una reducción en los salarios del personal creativo de algunas de las editoriales supervivientes: en el caso de Charlton Comics, que además tuvo que lidiar con la inundación de sus instalaciones en 1955, el sueldo de los autores se vio reducido a la mitad (Gill, 2000); en Timely Comics, algunos dibujantes pasaron en cuestión de pocos meses de cobrar cuarenta y cuatro dólares por página a tan solo veinticuatro (Romita, 2001). La segunda consecuencia fue la reducción de la oferta de trabajo, por lo que los autores no podían compensar los bajos sueldos aumentando la producción como habían hecho en los años treinta, como bien refleja el relato del dibujante Don Heck: "Estuve trabajando en exclusiva para Marvel hasta mayo de 1957. Recuerdo ir a la ciudad y enviar a mi mujer a las oficinas tras decirle: «Que te digan qué tengo que dibujar», pero al regresar me dijo: «No tienen nada». Fue una sorpresa (...)” (Heck, 2011). Las escasas oportunidades de trabajo y la pérdida de poder adquisitivo conllevaron la marcha de muchos autores veteranos, que 
trabajaron en los empleos más variados, desde ilustrador de modelos de aviones (Heck, 2011) e ilustrador de libros (Bellman, 2005) hasta cartero (Flessel, 2008); al mismo tiempo, los nuevos autores en potencia que podían haberse dirigido hacia la industrial del comic book acabaron optando por otras opciones más seguras o mejor pagadas.

Pero como ya vimos que pasó en los primeros años de la industria del cómic, una situación de crisis también presenta oportunidades para modificar la forma de producción. Este cambio se dio en Marvel Comics (un nombre nuevo, pero que escondía lo que quedaba de la malograda Timely Comics), una pequeña editorial que había pasado de ser una de las más prolíficas de la industria a publicar tan solo un puñado de cómics mensuales, contando únicamente con un editor que también se ocupaba de crear los guiones, Stan Lee, y un encargado de montaje, Larry Lieber; todo el proceso editorial tenía lugar en una pequeña oficina, ya que los dibujantes trabajaban desde casa (Lieber, 1999). Esta forma de producir cómics funcionaba sobre el papel, pero en la práctica Lee concentraba en su persona tareas creativas, editoriales y administrativas, dándole una carga excesiva de trabajo que intentó remediar a través de una transformación del método creativo:

Di con este sistema en el que no necesita escribir un guión completo, que es lo que se escribe para una película o una serie de televisión, sino que en su lugar discutía la historia con el dibujante. Le contaba la trama, y entonces le pedía que la plasmara de la manera que considerase más adecuada. Cuando me entregaba las páginas dibujadas, yo escribía los diálogos y los textos de apoyo (...). Lo hacía así porque era la única manera de conseguir que las series estuviesen listas a tiempo (...), pero con el tiempo me di cuenta de que era la forma más adecuada de trabajar. Nuestros dibujantes eran realmente buenos contando historias: tenían una gran habilidad para narrar en imágenes, y con este método de trabajo podían contar la historia de la manera que ellos considerasen más apropiada. El dibujante es quien mejor sabe cómo puede dibujar una página, así que obtenía lo mejor de ellos... De este modo, cuando recibía los dibujos, todo lo que tenía que hacer era añadir los diálogos para que encajaran de la mejor manera posible con los dibujos. Esto hizo mucho más interesante el trabajo para mí, y también para los dibujantes, y creo que hizo que los cómics que hacíamos fuesen mejores (Lee, 2000).

Es probable que en un primer momento los dibujantes no se encontrasen muy cómodos con un sistema que, a fin de cuentas, les exigía una mayor implicación a cambio del mismo sueldo, aunque la escasez de trabajo les hizo aceptar. Sin embargo, a medida que fueron acostumbrándose al sistema, también ellos sintieron que era la mejor manera de trabajar, como reconocía el dibujante Don Heck:

Estaba acostumbrado a trabajar con guiones [tradicionales], pero Stan me dijo cuando regresé a Marvel: «Voy a darte una sinopsis». (...) Stan Lee solía contarte las tres primeras páginas, decirte que el personaje estaba luchando, y contarte las dos últimas páginas para que supieses cómo acababa todo. Las quince páginas de entremedio las tenías que idear tú.

En un primer momento pensé: «¡Dios mío! ¡Es imposible que esto salga bien!». Pero entonces me puse a trabajar y empecé a pensar qué podían hacer los personajes. Muchos años después, cuando volví a trabajar con guiones [tradicionales], me sentía en ocasiones maniatado. Me había acostumbrado al sistema de las sinopsis, y deja que te diga el porqué: (...) es la forma de trabajar que te da más libertad. (2011). 
También John Buscema, otro de los dibujantes clásicos de Marvel en los años sesenta y setenta, alababa este nuevo sistema de trabajo: "La única diferencia entre Marvel y DC es que ellos trabajaban con un guión completo mientras que nosotros trabajábamos con unas ideas generales que nos daban muchísima más libertad. Y esa es la única forma de hacerlo, porque un guionista no puede visualizar la historia igual que lo hace un dibujante” (Buscema, 2002).

Además, aunque esta forma de producción no estaba mejor remunerada, los cómics de Marvel sí identificaban con sus nombres y apellidos a todos los miembros del equipo creativo (guionista, dibujante, entintador, rotulista, colorista y editor), además de permitirles mantener un estilo propio y personal. Por ello, tanto por la libertad creativa ofrecida como por el reconocimiento obtenido, esta forma de trabajar tuvo un efecto patente sobre el producto final, que se desligó en buena medida de las fórmulas y permitió que cada autor desarrollara su propio estilo, atrayendo a causa de ello un núcleo fiel y creciente de lectores que hicieron mejorar las ventas (Wolfman, 2001). Así, frente a los menos de 200.000 ejemplares de cualquiera de sus series que Marvel vendía en 1961, en 1966 algunos de sus títulos rozaban ya los 350.000, un incremento grande que aún era mayor si tenemos en cuenta que la mayoría de las editoriales estaban perdiendo lectores (Comichron, s/f).

El aumento de ventas trajo una mejora de los ingresos de la editorial, pero la expansión de títulos obligó a contratar a nuevos dibujantes, guionistas y editores. El editor Roy Thomas, que había comenzado su carrera de guionista bajo la supervisión de Stan Lee, supo apreciar el método de trabajo de este y apostó por continuar usándolo, dando la mayor libertad posible a sus guionistas y dibujantes: "Nunca me gustó meterme en el trabajo de los demás. Mi planteamiento era contratar a buenos autores y simplemente corregirles la ortografía” (2005). Esta práctica la confirma Steve Gerber, guionista que ejerció como editor asociado a mediados de los años setenta, y que explicaba así su papel editorial: "El cargo de editor asociado era poco más que un título (...). Leía los cómics [y] buscaba errores en el dibujo [y] en los bocadillos” (Gerber, 2001). Además, frente a los espacios de trabajo abarrotados y el ambiente de aula que algunos autores habían señalado que reinaban en los años treinta, los editores de Marvel dieron gran libertad a sus autores con tal de que entregasen su trabajo a tiempo. Cierto es que la necesidad de que los autores trabajaran fuera de las oficinas de la editorial surgió a causa del pequeño espacio del que Marvel disponía, pero cuando la empresa se trasladó a otras oficinas más amplias, se continuó confiando en la profesionalidad de su personal, como señalaba el dibujante Herb Trimpe: “Comencé a dibujar el título The Hulk en la oficina. Los dos primeros números los hice allí, hasta que un día le comenté a Stan que me costaba concentrarme, a lo que me respondió: «Bueno, ¿por qué no trabajas desde casa?». Así lo hice (...). Era la libertad absoluta” (2001).

En general, la motivación de los autores de Marvel Comics se muestra como extremadamente alta, siendo obvio el gran interés por el trabajo que realizaban. De hecho, en los años setenta Marvel empezó a contar con jóvenes talentos que habían crecido durante la década anterior leyendo sus cómics, y que ahora ambicionaban trabajar con los personajes que admiraban (Stern, s/f). En parte esto se debe a la cierta estabilidad que ofrecía la editorial, pues las licencias de sus personajes (televisión, juguetes, libros, etc.) y las ventas de los derechos de sus cómics en el extranjero ayudaron a contrarrestar la caída de ventas causada por el aumento de los precios debido a la crisis del petróleo de los años setenta y el aumento del desempleo (Wright, 2003); a diferencia de los autores que trabajaban en otras editoriales, el personal de Marvel tenía la confianza de que la empresa para la que trabajaba seguía siendo una operación rentable. 
Pero a pesar de todos estos elementos positivos que animaban a los autores y les ayudaban a dar lo mejor de sí mismos, Marvel Comics seguía lastrada por muchas inercias que procedían del sistema de gestión editorial tradicional. Uno de los problemas básicos era la tarifa que se pagaba por página: un guionista podía cobrar unos 20 y 25 dólares por página, mientras que los dibujantes mejor pagados cobraban 100, cifras que no son tan fabulosas como parecen si tenemos en cuenta que los autores no tenían seguro médico ni plan de jubilaciones, que tenían que pagarse ellos mismos (Shooter, 2011e); además, el dinero que ganaban era el mismo independientemente de que su trabajo mejorase las ventas de una serie o de que el personaje que habían creado fuese un éxito. Por lo tanto, muchos autores necesitaban trabajar en varias series para poder tener un sueldo digno y estar preparados contra eventualidades como una enfermedad; el ritmo de trabajo del guionista Doug Moench es un buen ejemplo de la carga de trabajo que podía llegar a tener un autor:

Me preguntaron [en Marvel] si me interesaba escribir algunos cómics. Me dieron Man-Wolf, Monster of Frankenstein y Werewolf by Nigh, y tras eso me siguieron ofreciendo más series para escribir. Parecía que me ofrecieran un nuevo título cada día. Master of Kung Fu, Iron Fist y más (...). Después de aproximadamente un mes, Roy [Thomas] me llamó a su despacho y me dijo que en Marvel necesitaban aún más guiones (...). Me caía de la cama para aterrizar en la silla de mi escritorio, literalmente. Vivía con mi futura esposa, y se portó estupendamente. Me traía una taza de café tras otra, hacía la comida, las compras y la limpieza, se ocupaba de todo. Yo prácticamente no hacía otra cosa que no fuera escribir desde el momento en que me levantaba hasta el momento en que caía rendido. Algunos días me iba a la cama a las 9:00 de la mañana y me levantaba a las 15:00 (2005).

Esta urgencia por producir, explicada por la rápida expansión de los títulos de la editorial durante los años setenta, afectaba no solamente a los autores, sino también al personal editorial. De este modo, cuando los directivos de la editorial decidieron en 1975 que debían publicarse cuatro nuevos títulos a principios del mes siguiente, el director editorial Len Wein salió con el resto de su pequeña plantilla editorial a almorzar para concebir las series que iban a publicarse y reunió a los equipos creativos por la tarde, de tal forma que al día siguiente ya pudiesen comenzar a trabajar (Raphael y Spurgeon, 2003). Este modo de crear cómics no se diferenciaba en nada del que tenían en otras editoriales, como en DC Comics, donde el escritor Bob Haney era el encargado de desarrollar personajes y series por las que no cobraba ningún dinero extra: "Era una forma asquerosa de trabajar, porque (...) no te daban ninguna compensación más allá de que te contratasen para escribir la serie si les parecía viable” (Haney, 1997). Obviamente esto hacía que algunos autores, entre ellos el propio editor Roy Thomas, no sintiesen motivación alguna por crear conceptos nuevos: "No me gustaba crear demasiados personajes para Marvel porque sabía que no iba a tener ningún derecho sobre ellos (...)” (2007). Es decir, Marvel estaba mejor que el resto de las editoriales, pero el trabajo podía llegar a ser extenuante y la compensación recibida no tenía realmente en cuenta el talento ni la creatividad de los artistas.

Esto creaba dos problemas. A largo plazo significaba que los autores podían comenzar a buscar otros negocios creativos (como el cine, la literatura o la televisión) a medida que fueran envejeciendo y buscasen mayor estabilidad, cosa que hicieron veteranos de la industria como Stan Lee y Jack Kirby (Stern, s/f). A corto plazo se estaba produciendo ya en esos momentos un agotamiento de los autores, que presionados por las fechas de entrega empezaban a ofrecer productos de menor calidad artística, como señalaba el por aquel entonces editor adjunto Jim Shooter: 
Algunos creativos (...) se sentían orgullosos de su trabajo, por lo que preferían arreglar ellos mismos cualquier error que se les señalara antes que dejarme a mí retocar su trabajo. Muchos otros escritores y dibujantes no mostraban esa integridad. Estaban enfrascados en el próximo guión o dibujo, y no podría haberles interesado menos lo que pasase con el que ya habían entregado, no dedicándole ni un minuto a corregir los errores que les señalaba. Hay que recordar que se cobraba exclusivamente por página en aquellos días. A más páginas entregases, más dinero cobrabas. Así que era usual que el trabajo de hacer retoques recayese sobre mí (Shooter, 2011a).

Por lo tanto, aunque la libertad creativa obtenida por los autores de Marvel Cómics era un avance, y a pesar de que se había a comenzado a producir cierto reconocimiento artístico al incluirse en cada cómic el nombre de las personas implicadas en la realización de las historietas, seguía quedando pendiente tanto el tema de los derechos de autor como el de ofrecer unas remuneraciones más equitativas a los autores.

\section{EL MODELO DE PRODUCCIÓN BASADO EN LOS AUTORES (1979- ACTUALIDAD)}

Si durante la primera mitad de los años setenta el agotamiento y la desilusión del personal creativo empezó a hacerse patente, durante la segunda mitad de la década este desencanto se canalizó hacia las propias editoriales. El por aquel entonces guionista y editor de Marvel Comics, Jim Shooter, vivió de primera mano aquel malestar, cuyo detonante considera que estuvo en el empeoramiento de la situación económica del personal creativo, pero también en las cada vez menores expectativas de futuro:

Las ventas de cómics no dejaban de caer en toda la industria [durante los años setenta], incluso en Marvel. Las principales editoriales se habían visto forzadas a reducir el número de títulos que publicaban, prescindir de personal y apretarse el cinturón. El sueldo del personal creativo era abismal, existían escasos beneficios [sociales] y la moral era baja (...). Lo más terrorífico, no obstante, era la enorme hostilidad del personal creativo hacia las empresas, que no dejaba de crecer. Muchos autores habían entrado a la industria como fans. Al principio quedaron aturdidos por las condiciones de mierda. Luego, su desilusión se transformó en ira (...) (Shooter, 2011a).

La relación de trabajo entre la editorial y el personal creativo no había cambiado entre los años treinta y los setenta. Los autores seguían trabajando por encargo en calidad de autónomos, y la ley establecía que en ese tipo de relaciones todo aquello que se creara pertenecía a la empresa que había realizado el encargo, en este caso las editoriales; esto significaba que se podía prescindir de un autor de un día para otro y que la explotación de los personajes a través de licencias (para crear juguetes, vender los cómics en otros países o realizar series de televisión) no reportaba ningún beneficio a los creadores de un personaje (desde el punto de vista legal). En otras épocas esta forma de trabajo había sido aceptada por la mayoría de los autores, pero en los setenta se empezó a forjar una conciencia entre el personal creativo del dinero que estaban ganando las editoriales con sus personajes, empezando los primeros movimientos de resistencia. Así, cuando la ley cambió en 1978 y Marvel quiso que sus empleados firmasen un documento que reconociese explícitamente que todo aquello que los autores crearan sería propiedad de la editorial, hubo una auténtica revuelta en las oficinas, con autores negándose a firmarlo. El ascensor del edificio donde Marvel tenía sus oficinas amaneció empapelado con copias del documento, y pintadas sobre 
cada una de ellas, con grandes letras rojas, se podía leer: "Firma este documento y estarás tirando tu vida por la borda” (Shooter, 2011d).

Dos elementos se habían conjugado para que los autores tuvieran una mayor conciencia. El primero de ellos había sido la irrupción de Atlas Comics, una nueva editorial que entre 1974 y 1975 intentó hacerse un hueco en la industria del cómic, para lo cual planteó una mejora de las condiciones de trabajo de modo que atrajese al personal creativo descontento de otras editoriales. Entre estas mejoras estaban tarifas por página más altas, como explicaba el dibujante Ernie Colon: "[Atlas Comics] me pidió que dijera cuánto cobraba por dibujar una página, y cuando les respondí una cantidad algo inflada, me dijeron: «Oh, no, eso no puede ser... Eres demasiado bueno para cobrar eso», ¡así que añadió cuarenta dólares a mi precio por página! ¡Era muchísimo dinero, un gran aumento!” (2001). Pero otras mejoras, las más importantes, fueron la posibilidad de recuperar los dibujos originales (que podían venderse a coleccionistas para complementar el sueldo) y la promesa de participar en los beneficios de la editorial (Amendola, 2001). Puesto que Atlas Comics se mantuvo apenas medio año en el mercado y sus ventas nunca fueron excepcionales, muchos de estos beneficios no tuvieron un efecto duradero o, en ocasiones, ni siquiera llegaron a aplicarse, si bien no es descabellado pensar que sentaron en los autores la idea de que las editoriales podían ofrecerles, si querían, mejores condiciones económicas.

El segundo elemento que influyó decisivamente fue el anuncio durante la segunda mitad de los años setenta de una superproducción cinematográfica de Superman. Jerry Siegel, cocreador del personaje, aprovechó ese momento para comenzar a escribir a diferentes medios de información la historia de cómo DC Comics se beneficiaba de su creación, mientras que él y su compañero, Joe Shuster, no recibían ningún tipo de compensación desde hacía tres décadas. Tras aquel primer paso, diversos dibujantes prestigiosos y con buena acogida entre la cada vez más amplia comunidad de aficionados al mundo del cómic comenzaron una campaña de apoyo a los creadores del hombre de acero, dándole una repercusión cada vez mayor a la historia. La propietaria de DC Comics, Warner Bros., comprendió rápidamente la mala prensa que estaba generando aquella historia, por lo que (a pesar de no tener la obligación legal de compensar a Siegel y Shuster) acabó acreditando nuevamente a los autores en cada cómic en el que apareciese el personaje y, además, les concedió pensiones vitalicias (Daniels, 1998). Tras este éxito, otros autores empezaron a plantearse la posibilidad de llevar a juicio a las editoriales para las que trabajaban con la intención de recuperar los derechos de los personajes que habían creado, tal y como fue el caso de Steve Gerber, guionista de Marvel Comics (Gerber, 1978).

Por lo tanto, los avances en la forma de remunerar a los autores que había hecho Atlas, más la victoria de los creadores de Superman, favorecieron entre el personal creativo el sentimiento de que podían exigir mejores condiciones a las editoriales. La posibilidad de una huelga era cada vez mayor, y de hecho Marvel Comics se encontraba en la práctica ante una, ya que un número importante de autores se negaba a firmar el documento de cesión de derechos anteriormente citado, por lo que la cantidad de autores con los que podía contar se redujo drásticamente. La única razón por la que la situación no siguió escalando y desembocó en una auténtica crisis fue que DC Comics tuvo que cancelar en 1978, a causa de las malas ventas, más de veinticinco series, creando una situación de pánico entre el personal de dicha editorial, que acudió a Marvel Comics pidiendo trabajo y dispuesta a firmar cualquier documento, despertando al mismo tiempo el pánico entre el personal de Marvel, que también aceptó firmar la cesión de derechos ante la posibilidad de que Marvel contase con los autores que venían desde DC (Shooter, 2011e). Con todo, las editoriales habían salvado la situación por puro azar; sin una mejora real de la situación de los autores, era previsible que las quejas 
volvieran aparecer en un futuro no muy lejano. Fue por ello que James Galton y Jenett Kahn, los nuevos directivos de las dos grandes editoriales supervivientes, Marvel y DC, decidieron realizar cambios estructurales importantes.

Pero ¿había dinero para un cambio de política? Durante los años anteriores posiblemente no, pero en 1979 se estaba consolidando un cambio en la forma de distribución de los cómics, que empleaba ahora un proceso más racional en el que los vendedores pedían el número exacto de copias que deseaban recibir, por lo que las editoriales ya no necesitaban imprimir grandes tiradas y ahorraban en costes de impresión (Seuling, 2005); de este modo, a pesar de vender menos cómics que en las décadas anteriores, el abaratamiento de la producción significaba que las editoriales estaban ganando más dinero.

Jenett Kahn impuso en DC Comics una política de incentivos por ventas, aunque para beneficiarse de ella era necesario conseguir unos resultados comerciales tan buenos que apenas dos series de la editorial se beneficiaban de dicha política (Shooter, 2011c). En Marvel, el presidente James Galton también estaba dispuesto a hacer cambios: "Puesto que yo venía de la industria del libro, la idea de compartir beneficios con los autores no me era ajena. Cuando Jim [Shooter] me sugirió hacerlo, me pareció lógico” (Daniels, 1991). Shooter se encontró entonces ante el reto de crear un plan de incentivos que pusiera fin a los choques con los autores, pero que al mismo tiempo fuera realista:

Logré el visto bueno para empezar a desarrollar un plan de incentivos para dibujantes y escritores basado en las ventas de los cómics y un plan para compartir con los autores los beneficios generados por los personajes que crearan, de tal modo que se fomentase el desarrollo de nuevos personajes (...). Desarrollar un plan que fuera justo y pudiese funcionar resultó más difícil de lo que había imaginado. Llevó tiempo. Pero mientras tanto, conseguí que aumentasen la tarifa por página que se pagaba a los autores (...). Además de los aumentos de tarifa, pedí que mejorasen los beneficios de la mayoría de los autores que trabajaban para nosotros asiduamente, por ejemplo dándoles un seguro de vida y un seguro médico. Aumentamos el dinero que se pagaba por la reedición de material antiguo, empezamos a cubrir los gastos de desplazamiento de los autores y a pagarles el material que utilizaban para su trabajo. Con estas mejoras conseguimos poner fin a la relación hostil que había existido entre el personal creativo y la empresa (Shooter, 2011a).

Esta política de premiar a los autores pronto se convirtió en clave: los mejores autores querían trabajar con las editoriales que les dieran un trato más favorable, por lo que la remuneración y los beneficios eran elementos a tener muy en cuenta por las empresas. De este modo, los incentivos se convirtieron no solamente en una forma de evitar conflictos, sino también en una manera de atraer autores de otras editoriales. El sistema pronto se perfeccionó para que los beneficios por ventas afectasen a todo el equipo creativo, incluso a los editores, hasta el punto de que la gratificación por ventas podía llegar a ser superior al sueldo original por hacer el cómic (Chichester, 2013). Se premiaba así, no solamente a quien concebía personajes o historietas populares, sino también a todas las personas implicadas en un cómic que resultase popular.

Ahora bien, estas mejoras vinieron con una limitación, y es que las editoriales, que cada vez tenían más intereses fuera de la industria del cómic, aplicaban un control cada vez mayor sobre los personajes y sus historias. En DC Comics esto se notó menos porque la libertad creativa de los años sesenta y setenta había sido limitada, pero en Marvel Comics los autores sí que notaron la pérdida de buena parte de la libertad que habían disfrutado en las dos 
décadas anteriores. No obstante, como señalaba el editor Tom De Falco, esta decisión no era arbitraria, sino que buscaba proteger los activos de las editoriales: "Quieres mantener a tus creativos felices, pero no puedes darles control absoluto sobre los personajes porque, al final, eso podría dañarlos. El editor debe preocuparse de los personajes a largo plazo, porque los creativos piensan en el ahora" (De Falco, 2007). No obstante, la mejora de las condiciones de los autores fue incentivo suficiente para superar los problemas creados, dando lugar a un modelo de producción y remuneración que aún hoy se emplea en la industria del cómic.

\section{CONCLUSIONES}

Los inicios de la industria del cómic en los años treinta se vieron condicionados por las penurias de la Gran Depresión, que hicieron que un trabajo a priori poco seguro y enormemente demandante se volviese atractivo a ojos de unos jóvenes que hasta aquel momento habían tenido pocas esperanzas de hallar un empleo. Poco importaba que las editoriales no reconocieran los derechos de autor, constriñesen la creatividad o empleasen un sistema de trabajo más similar al de una cadena de montaje de coches que al de una empresa creativa: un autor trabajador podía conseguir más dinero del que habría logrado en otro negocio, incluso si empezaba sin ningún tipo de experiencia previa.

Es posible que las duras condiciones de los años treinta hubiesen supuesto un problema a la larga, pero el hecho fue que el aumento de las editoriales y la mejora de las ventas llevó en los años cuarenta a que las editoriales mejorasen los sueldos y diesen un trato favorable a sus mejores autores, ya fuese como una forma de reconocimiento a su labor, ya fuese para evitar que se marcharan a la competencia. De este modo, el personal creativo percibió una mejora con respecto a su situación en la década anterior, evitando cualquier tipo de protesta abierta contra la industria; los pocos autores que no aceptaron la situación se vieron rápidamente excluidos de la industria tras unos procesos judiciales que en modo alguno satisficieron sus reclamaciones.

Es imposible saber hacia dónde habrían evolucionado los sistemas de producción y las condiciones de trabajo en los años cincuenta de no haberse producido la fuerte crisis que sacudió a la industria del cómic, pero lo que sí puede afirmarse es que la marcha de autores y la reducción de ventas creó un nuevo panorama inédito al que muchas editoriales no fueron capaces de enfrentarse. Marvel Comics ingenió un sistema de trabajo que en un primer momento le ahorraba contratar más guionistas, si bien a costa de aumentar los deberes de los dibujantes; no obstante, la medida fue bien recibida tras los temores iniciales porque ofrecía a los dibujantes una libertad artística de la que nunca antes habían disfrutado, algo que vino acompañado de algo tan simbólico como era la acreditación de su trabajo en las historietas. Cuando Marvel mejoró su situación económica, no dudó en contratar más escritores, si bien hubo durante buena parte de los años sesenta y setenta una política de laissez faire que garantizó la libertad creativa.

Pero el sistema de producción de Marvel, aunque atrajo a numerosos autores jóvenes y veteranos, poseía los mismos frágiles cimientos que el resto de las editoriales de los años setenta: no existían beneficios sociales para los autores, el éxito de ventas de una serie no repercutía directamente en el sueldo de sus autores y la creación de nuevos personajes o conceptos no era premiada en modo alguno; en una época en la que los personajes de las editoriales daban el salto a la televisión y se publicaban en muchos países fuera de los Estados Unidos, esta situación comenzó a crear cada vez mayor malestar.

La reducción del número de títulos y editoriales, sumada a la conciencia cada vez mayor de los autores, que habían visto cómo DC Comics terminaba reconociendo y compensando a 
los creadores de Superman, llevó a un malestar que no hizo más que aumentar durante los años setenta. La promesa de Atlas Comics de ofrecer una parte de los beneficios a los autores, si bien nunca llegó a materializarse debido a la desaparición de la editorial, obviamente creó unas expectativas que condujeron al personal creativo a reivindicar mejores condiciones de trabajo, un mayor reconocimiento y remuneraciones más justas. En el caso de Marvel Comics, la tensión llegó a tal nivel que en la práctica estalló una huelga, ya que muchos autores se negaron a firmar una declaración de cesión de derechos, dejando sin personal creativo a la empresa, que finalmente salió airosa gracias al cierre masivo de títulos en DC Comics, lo que creó tal pánico entre los autores que puso fin a sus reticencias.

Con todo, tanto en Marvel como en DC fueron conscientes de que era necesario poner fin al problema que tenían con sus propios empleados, desarrollando un sistema de incentivos que no solo pagara más a los autores, sino que premiara a aquellos que realizaran un trabajo excepcional que repercutiese en unas buenas ventas. El atractivo del sistema era doble: servía para atraer a los autores de la competencia y, al mismo tiempo, hacía que los autores diesen lo mejor de sí mismos, lo que era de esperar que repercutiese en unas mayores ventas.

Por lo tanto, lo que encontramos en la evolución del sistema de trabajo y remuneración de la industria del cómic estadounidense es una única constante: la necesidad del personal creativo de encontrarse satisfecho. Al mismo tiempo, esta satisfacción puede deberse a dos condicionantes: la libertad para desarrollar su trabajo de la manera que consideren más adecuada y los beneficios tanto económicos como de reconocimiento que dicho trabajo le reporten. En épocas de crisis económica grave, como la Gran Depresión, la mejora progresiva de salarios favoreció que los autores se encontrasen a gusto en la industria del cómic, encontrando, por lo tanto, pocos casos de enfrentamiento con las editoriales, y eso a pesar de la injerencia de los editores, la escasa libertad creativa y el aún menor reconocimiento. Por el contrario, cuando se produce un retroceso en la remuneración, se crean situaciones de conflicto, que pueden suponer el abandono de los autores a otros medios (como sucedió en los años cincuenta y posteriormente, en menor medida, en los setenta) o el choque con la editorial (como sucedió en los años setenta). Marvel Comics consiguió salvar dicho problema con un aumento de la libertad creativa durante los años sesenta, pero cuando los recortes provocados por la crisis de la década siguiente golpeó a todas las editoriales, las demandas artísticas perdieron importancia y los autores se aferraron a los aspectos puramente económicos; de hecho, la pérdida de libertad creativa experimentada a partir de 1979 no despertó rechazo significativo.

No obstante, esto no quiere decir que la libertad creativa no fuera importante: los autores la tienen presente en sus declaraciones y, en la Marvel de los años sesenta y setenta, era uno de los aspectos que los autores más comentaban. Lo que sucede es que la estabilidad económica se perfila como el objetivo más importante de los autores y, por lo tanto, es el elemento que más puede dañar o favorecer las relaciones entre el personal creativo y las editoriales. Pero esto deja otras preguntas abiertas para futuras investigaciones: ¿qué sucedió a partir de los años ochenta, cuando el reconocimiento de los derechos y los incentivos económicos estuvieron garantizados? ¿Qué conflictos se generaron cuando editoriales y autores no coincidieron en el rumbo de una historia? ¿Hasta dónde estaban dispuestos a llegar los autores para poseer mayor libertad creativa?

\section{BIBLIOGRAFÍA Y FUENTES}

\section{Entrevistas y declaraciones:}

Amendola, S. (2001): Entrevistado por Jon B. Cooke en Comic Book Artist, 16, pp. 78-87. 
Beck, C.C. (1980): Entrevistado por Tom Heintjes en Hogan's Alley, consultada el 4 de abril de 2010, http://www.cagle.msnbc.com/hogan/interviews/beck/home.asp.

Bellman, A. (2005): Entrevistado por Michael J. Vassallo en la revista online Comic Art Ville, subido en 2005 y consultado el 16 de agosto de 2008, http://www.comicartville.com/bellman.htm.

Buscema, J. (2002): Entrevistado por Mark Evanier en Alter Ego n. ${ }^{\circ}$ 15, Two Morrows Publishing, Raleigh (EE UU), pp. 4-25.

Chichester, D.G. (2013): Entrevistado por el autor del artículo entre el 16 y el 22 de abril de 2013.

Colon, E. (2001): Entrevistado por Jon B. Cooke en Comic Book Artist, 16, pp. 44-53.

De Falco, T. (2007): Entrevistado en Khoury, G.A.: Image Comics. The Road of Independence, TwoMorrows, Raleigh (EE UU), pp. 138-143.

Eisner, W. (1997): Entrevistado por Jean Depelley en The Jack Kirby Collector,16, pp. 14-15.

Fago, V. (2001): Entrevistado por Jim Amash en Alter Ego n. ${ }^{o}$ 11, TwoMorrows, Raleigh (EE UU), pp. 8-27.

Flessel, C. (2008): Entrevistado por la redacción de The Silver Age Sage, <http://www.wtvzone.com/silverager/sasar9/archive193.shtml> (consultado el 10/12/2012).

Gerber, S. (1978): Entrevistado por Gary Groth en The Comics Journal, 52, $<$ http://www.tcj.com/the-steve-gerber-interview/> (consultado el 6/8/2012).

Gerber, S. (2001): Entrevistado por Jon B. Cooke en Comic Book Artist Collection Volumen 3, pp. 54-67.

Gill, J. (2000: Entrevistado por Christopher Irving en Comic Book Artist, 9, pp. 22-24.

Haney, B. (1997): Entrevistado por Michael Catron para la web The Comics Journal, $<$ http://classic.tcj.com/superhero/bob-haney-interviewed-by-michael-catron-part-oneof-five/> (consultada el 28/8/2016).

Hasen, I. (1999): Entrevistado por Roy Thomas en Alter Ego, 1, pp. 2-13.

Heck, D. (2011): Declaraciones publicadas en la web $20^{\text {th }}$ Century Danny Boy, http://ohdannyboy.blogspot.com/2011/05/original-art-stories-don-heck-in-his.html (consultado el 10/1/2012).

Kirby, J. (1990): Entrevistado por Gary Groth en The Comics Journal, 134, $<$ http://www.tcj.com/jack-kirby-interview/> (consultado el 22/6/2012).

Kirby, J. (2005): Entrevistado por Will Eisner en Eisner, W.: Shop Talk: Conversaciones con Will Eisner, Norma Editorial, Barcelona (entrevista realizada en julio de 1982), pp. 193-224.

Kubert, J. (2005): Entrevistado por Will Eisner en Eisner, W.: Shop Talk: Conversaciones con Will Eisner, Norma Editorial, Barcelona, pp. 225-259.

Lieber, L. (1999): Entrevistado por Roy Thomas en Alter Ego, 2, pp. 18-31.

Mayer, S. (1975): Entrevistado por Anthony Tollin en Amazing World, 5, pp. 2-12.

Moench, D. (2005): Entrevistado en De Falco, T.: Comics Creator on Fantastic Four, Titan Books, Londres (Reino Unido), pp. 74-87.

Moldoff, S. (2000): Entrevistado por Roy Thomas para la web TwoMorrows, $<$ http://twomorrows.com/alterego/articles/04moldoff.html> (consultado el 8/6/2011). 
Renée, L. (2006): Entrevistada por Trina Robbins en la web The Comics Journal, $<$ http://www.tcj.com/index.php?option=com_content\&task=view\&id=466\&Itemid=48 $>$ (consultada el 9/5/2009).

Romita, J. (2001): Entrevistado por Roy Thomas en Alter Ego, 9, pp. 4-38.

Seuling, P. (2005): Entrevistado por Will Eisner en Eisner, W.: Shop Talk: Conversaciones con Will Eisner, Norma Editorial, Barcelona, pp. 283-306.

Shooter, J. (2011a): "The Impending Death of the Comics Industry" en el blog Jim Shooter,

$<$ http://www.jimshooter.com/2011/03/impending-death-of-comics-industry.html> (consultado el 15/6/2011).

Shooter, J. (2011b): "ROM Comments and Answers", en el blog Jim Shooter, $<$ http://www.jimshooter.com/2011/06/rom-comments-and-answers.html> (consultado el 20/6/2011).

Shooter, J. (2011c): “And now, a few positive words about Marvel Financial V.P. Barry Kaplan”, en el blog Jim Shooter, <http://www.jimshooter.com/2011/06/and-now-fewpositive-words-about-marvel.html $>$ (consultado el 21/6/2011).

Shooter, J. (2011d): “The Secret Origin of Jim Shooter, Editor in Chief - Part 3”, en el blog Jim Shooter, <http://www.jimshooter.com/2011/06/secret-origin-of-jim-shootereditor-in_29.html> (consultado el 29/6/2011).

Shooter, J. (2011e): “The Secret Origin of Jim Shooter, Editor in Chief - Part 4”, en el blog Jim Shooter, <http://www.jimshooter.com/2011/06/secret-origin-of-jim-shootereditor-in_30.html> (consultado el 30/6/2011).

Shooter, J. (2011f): "Writer/Editors - Part 3" en el blog Jim Shooter, $<$ http://www.jimshooter.com/2011/08/writereditors-part-3.htmll> (consultado el 16/8/2011).

Simon, Joe (2008): Entrevistado por la redacción de The Silver Age Sage, <http://www.wtvzone.com/silverager/interviews/simon.shtml> (consultado el 8/8/2012).

Stein, I. (2007): Entrevistado en Benson, J.: Confessions, Romances, Secrets, and Temptations. Archer St. John and the St. John Romance Comics, Fantagraphics Books, Seattle (EE UU), pp. 8-23.

Stern, R. (s/f): Entrevistado por George Khoury en Marvel Masteworks Resource Page, $<$ http://www.marvelmasterworks.com/features/int_stern_1006_1.html> (consultado el 9/8/2009).

Thomas, R. (2005): Entrevistado por Tom De Falco en De Falco, T.: Comics Creator on Fantastic Four, Titan Books, Londres (Reino Unido), pp. 40-57.

Thomas, R. (2007): Entrevistado por Jim Amash en Alter Ego, 70, pp. 3-61.

Trimpe, H. (2001): Entrevistado por John B. Cooke en Comic Book Artist, 13, pp. 58-68.

Wexler, E. (2004): Entrevistado por Jim Amash en Alter Ego, 34, pp. 18-22.

Wolfman, M. (2001): Entrevistado por Jon B. Cooke en Comic Book Artist, 13, pp. 30-47. 


\section{Obras de consulta:}

Barrier, M. (1982): "El nacimiento del comic book: El largo camino hacia Famous Funnies y Superman", en Coma, J.: Historia de los Comics Volumen I, Toutain Editor, Barcelona, pp. 197-204.

Carlson, M. (2005): "Funny Business: A History of the Comic Industry" en The Nostalgia Zine, 1, <http://www.nostalgiazone.com/doc/zine/05_Q1/funnybusiness.htm> (consultado el 24/3/2013).

Comichron (s/f): "Comic Book Sales for Year" en Comichron, <http://www.comichron.com/yearlycomicssales.html> (consultado el 21/4/2016).

Kirby, J. (1991): Five Fabulous Decades of the World's Greatest Comics Marvel, Harry N. Abrams, Nueva York (EE UU).

Kirby, J. (1998): Superman: The Complete History, Chronicle Books, San Francisco (EE $\mathrm{UU})$.

Kirby, J. (1999): Batman: The Complete History, Chronicle Books, San Francisco (EE UU).

Kirby, J. (2003): DC Comics, a Celebration of the World's Favorite Comic Book Heroes, Billboard Books, Nueva York (EE UU).

Evanier, M. (2007): Kirby, King of Comics, Nueva York (EE UU), Abrams.

Feiffer, J. (2003): The Great Comic Book Heroes, Fantagraphics, Seattle (EE UU).

Lee, S. (1947): Secrets Behind the Comics, Nueva York (EE UU), autoedición.

Raphael, J. y Spurgeon, T. (2003): Stan Lee and the Rise and Fall of the American Comic Book, Chicago Review Press, Chicago (EE UU).

Rodríguez, J. (2014): “Una nueva mirada al ocaso de los superhéroes durante la Edad Dorada del cómic estadounidense (1944-1949)”, Revista de Historia Ubi Sunt? ,29, pp. 141152.

Savage, W. (1990): Comic Books and America, 1945-1954, University Oklahoma Press, Oklahoma (EE UU).

Simon, J. y Simon, J. (2003): The Comic Book Makers, Vanguard Productions, New Jersey (EE UU).

Vance, M. (2006): "Forbidden Adventures: The History of American Comics Group”, Alter Ego, 61, pp. 3-75.

Wright, B.W. (2003): Comic Book Nation: The Transformation of Youth Culture in America, The Johns Hopkins University Press, Baltimore (EE UU).

Zinn, H. (1999): La otra historia de los Estados Unidos, Argitaletxe Hiru, Hondarribia.

Zorbaugh, H. y Gilman, M. (1949): “What Can You Do about Comic Books?”, Family Circle, pp. 60-63. 